European Thyroid Journal
Eur Thyroid J 2017;6:113-114

DOI: 10.1159/000456660
Received: November 21, 2016

Accepted after revision: January 16, 2017

Published online: March 1, 2017

\title{
Selenium in the Treatment of Thyroid Diseases
}

\author{
Michele Marinò ${ }^{a} \quad$ Claudio Marcocci ${ }^{\mathrm{a}} \quad$ Paolo Vitti $^{\mathrm{a}}$ Luca Chiovato $^{\mathrm{b}} \quad$ Luigi Bartalena $^{\mathrm{c}}$ \\ ${ }^{a}$ Endocrinology Unit, Department of Clinical and Experimental Medicine, University Hospital of Pisa, \\ University of Pisa, Pisa, ${ }^{b}$ Unit of Internal Medicine and Endocrinology, Laboratory for Endocrine Disruptors, \\ Istituti Scientifici Maugeri IRCCS, University of Pavia, Pavia, and 'Endocrinology Unit, Department of \\ Clinical and Experimental Medicine, University of Insubria, Varese, Italy
}

Dear Editor,

In the September issue of the European Thyroid Journal, Negro et al. [1] reported on a survey carried out among members of AME (Associazione Medici Endocrinologi) and AACE (American Association of Clinical Endocrinologists - Italian Chapter) on the use of selenium in thyroid disease. Both Negro et al. [1] and, especially, Hegedüs et al. [2], in the accompanying Editorial $[1,2]$, underscored the abuse of selenium in thyroid disease.

There is no question that the use of selenium in autoimmune thyroiditis, as a measure to prevent the development of hypothyroidism [3] or to provide a benefit in patients already receiving levothyroxine, is not supported by unequivocal evidence. In this regard, prospective, possibly randomized, studies are needed, and we agree that selenium should not be given to patients with autoimmune thyroiditis until evidence for a beneficial effect is convincingly provided.

Concerning Graves hyperthyroidism, in our opinion there is some evidence supporting a possible use of selenium as an adjuvant measure in selenium-deficient patients treated with antithyroid medications. Calissendorff et al. [4] conducted a randomized clinical trial in which selenium was shown to provide a beneficial effect in terms of control of hyperthyroidism in a cohort of selenium-deficient patients treat- ed with methimazole and levothyroxine, according to the block-and-replace regimen. In another recent randomized clinical trial performed in selenium-sufficient patients, we did not observe a beneficial effect of selenium in patients with Graves hyperthyroidism treated with methimazole, in terms of short-term, prompter control of thyroid hyperfunction [5]. Based on the combined results of these two studies, we believe that selenium supplementation might be offered to patients with Graves hyperthyroidism only if selenium deficiency is documented.

Concerning Graves orbitopathy (GO), there is clear-cut evidence for a beneficial effect of selenium derived from a large randomized clinical trial performed by the European Group on Graves Orbitopathy (EUGOGO) in patients with mild GO [6]. Therefore, as suggested by the recently published EUGOGO guidelines on GO [7], a 6-month course of selenium can be offered to patients with mild GO. In the EUGOGO study serum selenium levels were not measured [6]. Therefore, it is not known whether the use of selenium should be restricted to patients with a proven selenium deficiency, which remains to be investigated.

It may be argued that there is only one study supporting the use of selenium for hyperthyroidism [4], and only one supporting the use of selenium for GO [6]. Clearly, additional studies would strengthen the indication for the use of selenium in both conditions.

One of the points of Hegedüs et al. [2] concerning a cautious and more restricted use of selenium in thyroid disease is the fear for side effects or adverse events, possibly linked to selenium overtreatment or to treatment with selenium of subjects that are already selenium sufficient $[2,8]$. However, in our recent study, as well as in the study from Calissendorff et al. [4] and in the EUGOGO study on GO $[5,6]$, no major side effects or adverse events were recorded for selenium doses not exceeding $200 \mu \mathrm{g} /$ day. It is worth noting that in our study side effects or adverse events were not observed in spite of the relatively high levels of selenium reached with treatment (approx. $190 \mathrm{ng} / \mathrm{mL}$ after 90 days of treatment), which is overall quite reassuring [5]. It is still possible that selenium may cause subclinical alterations that can be detected only by testing, for example concerning glucose metabolism, as reported previously [9], although the clinical impact of such alterations remains to be established.

In conclusion, although we agree that there is not sufficient or unequivocal evi-

\section{KARGER}

(C) 2017 European Thyroid Association

Published by S. Karger AG, Basel
Michele Marinò

Endocrinology Unit I, Department of Clinical and Experimental Medicine University Hospital of Pisa, Via Paradisa 2 IT-56124 Pisa (Italy)

E-Mail michele.marino@med.unipi.it 
dence for the use of selenium in autoimmune thyroiditis, we believe that there is evidence for its use in selenium-deficient patients with Graves hyperthyroidism, as well as in patients with mild GO, even though further studies are needed to strengthen these conclusions. Although it is possible that selenium may exert toxicity if given at very high doses [8], a dosage up to $200 \mu \mathrm{g} /$ day in selenium-deficient subjects, as in the study from Calissendorf et al. [4], or of $166 \mu \mathrm{g} /$ day in selenium-sufficient patients, as in our recent study [5], is in our opinion quite safe. In any case, it seems prudent to check selenium status prior to initiating therapy.

\section{References}

1 Negro R, Attanasio R, Grimaldi F, Marcocci C, Guglielmi R, Papini E: A 2016 Italian survey about the clinical use of selenium in thyroid disease. Eur Thyroid J 2016;5:164-170.

2 Hegedüs L, Bonnema SJ, Winther KH: Selenium in the treatment of thyroid diseases: an element in search of the relevant indications? Eur Thyroid J 2016;5:149-151.

3 Esposito D, Rotondi M, Accardo G, Vallone G, Conzo G, Docimo G, Selvaggi F, Cappelli C, Chiovato L, Giugliano D, Pasquali D: Influence of short-term selenium supplementation on the natural course of Hashimoto's thyroiditis: clinical results of a blinded placebo-controlled randomized prospective trial. J Endocrinol Invest 2017;40:83-89.

4 Calissendorff J, Mikulski E, Larsen EH, Möller M: A Prospective investigation of Graves' disease and selenium: thyroid hormones, autoantibodies and self-rated symptoms. Eur Thyroid J 2015;2:93-98.

5 Leo M, Bartalena L, Rotondo Dottore G, Piantanida E, Premoli P, Ionni I, Di Cera M, Masiello E, Sassi L, Tanda ML, Latrofa F, Vitti P, Marcocci C, Marinò M: Effects of selenium on short-term control of hyperthyroidism due to Graves' disease treated with methimazole: results of a randomized clinical trial. J Endocrinol Invest, Epub ahead of print.

6 Marcocci C, Kahaly GJ, Krassas GE, Bartalena L, Prummel M, Stahl M, Altea MA, Nardi M, Pitz S, Boboridis K, Sivelli P, von Arx G, Mourits MP, Baldeschi L, Bencivelli W, Wiersinga W: Selenium and the course of mild Graves' orbitopathy. N Engl J Med 2011;364:19201931.

\section{Disclosure Statement}

The authors have nothing to disclose.

7 Bartalena L, Baldeschi L, Boboridis K, Eckstein A, Kahaly GJ, Marcocci C, Perros P, Salvi M, Wiersinga WM: The 2016 European Thyroid Association/European Group on Graves' Orbitopathy Guidelines for the Management of Graves' Orbitopathy. Eur Thyroid J 2016;5:9-26.

8 Rayman MP: Selenium to human health. Lancet 2012;379:1256-1268.

9 Jablonska E, Vinceti M: Selenium and human health: witnessing a copernican revolution? J Environ Sci Health C Environ Carcinog Ecotoxicol Rev 2015;33:328-368. 